\title{
Very Light Jets: Requirements for Pilot Qualification and Collegiate Aviation's Role
}

\author{
Randal J. DeMik, R. Troy Allen, and Bruce W. Welsh \\ Indiana State University
}

\begin{abstract}
This study examined how senior flight operations staff at Very Light Jet (VLJ) air taxi and manufacturing companies determine pilot experience levels, training, education and qualifications for their current and future flight operations. Additionally, this study examined how collegiate aviation may address the pilot training and education needs of the VLJ industry. Senior flight operations staffs at two VLJ air taxi operators and three VLJ manufacturers were interviewed regarding these issues. Results indicated that current pilot supply for commercial operations in VLJ aircraft were being met by pilots leaving regional airline operations and also from promotion within respective respondents' current air taxi operations. Innovative mentoring programs designed for single-pilot VLJ commercial operations were not being routinely utilized in favor of the more traditional Captain and First Officer roles for gaining flight experience and advancement. Another operational implication for the traditional two-pilot crew versus single-pilot was to meet particular customer insurance requirements for multi-pilot crews. Respondents valued collegiate aviation's past preparation of industry pilots and offered suggestions in adjusting curriculum away from traditional rote systems training to one of cockpit management. Results indicated that while there was no immediate need for formal relationships between VLJ industry and collegiate aviation, respondents were open to the idea of future collaboration.
\end{abstract}

\section{INTRODUCTION}

Very Light Jets (VLJs) are being introduced to the aviation industry at an increasing rate. Because of the potential entry of VLJs over the next eight to ten years, there is some concern that these high performance jet aircraft, with advanced cockpit avionics, integrated automation features, and single-pilot operation, are particularly sensitive to the need for highquality training, selection and qualifying of pilots. The introduction of the VLJ into the commercial aviation industry will bring both new opportunities and demands to flight training and education. Applying what the industry has learned from the past, an innovative pilot selection, training, and qualifying process must be identified to ensure an orderly and safe transition for those who become commercial operators of this next generation of aircraft.

In this paper, we present a preliminary qualitative study for identifying initial pilot operating experience, qualifications, and training requirements, as determined by emerging commercial VLJ business operators and manufacturers. While federal regulators and aviation insurance companies have established initial minimum pilot requirements for VLJ commercial operation, it was the goal of this study to determine how VLJ business operators and manufacturers view these requirements in their actual operations.

This study was an Institutional Research Board (IRB) approved survey of VLJ flight operations staff that may provide insight to determine pilot experience levels, training, education and qualifications for their current and future flight operations and how collegiate aviation may address some of these concerns. Flight operations staff at VLJ air taxi companies included chief pilots and flight operations managers. Flight operations staff at VLJ manufacturers included flight staff within customer flight support, flight training, and flight testing. The purpose, literature review, methodology, findings, and conclusions of this study are presented in the following sections.

\section{PURPOSE OF THE STUDY}

The purpose of this study was to ascertain how commercial VLJ business operators and manufacturers view pilot selection, training and operational experience processes unique to VLJ single-pilot commercial operations. Additionally, this study investigated the role collegiate aviation could possibly play in preparing pilots 
for this emerging section of the aviation industry.

\section{LITERATURE REVIEW}

Very Light Jets are being introduced to the industry at an increasing rate. According to Honeywell's 2007 Business Aviation Outlook, the forecast is that approximately $5000 \mathrm{VLJ}$ will be produced between the years of 2007 and 2016 (Government Accountability Office, 2007). In this same GAO report, PMI Media predicts the production of VLJs to exceed 7,000 aircraft during the same time period. The report also cited the Federal Aviation Administration's (FAA) own estimates for that time period include the production of approximately 6,000 VLJs. Strait (2007) reports that manufacturers of VLJs have accepted advanced sales of nearly 3,000 aircraft.

Forecasts indicate that these trends will continue for the foreseeable future (Brown, 2007; Cobb, Thomas, \& Cobb, 2007). Research in the area of VLJs has followed several avenues. Early works by Trani, Baik, Swingle, and Senanu (2003) and Trani et al. (2005) were concerned with developing systems dynamics models for small jet aircraft integration into the airspace system and other socio-economic factors based on the introduction of VLJs. Cobb, Thomas, and Cobb (2007), reported on issues related to the direct and indirect market impact of VLJ aircraft. Additional work by Prather and Hawkins (2007), and Bonnefoy and Hansman (2007), dealt with the impact of VLJs on general aviation airports and the National Airspace System.

Few researchers have addressed the problems of hiring, training and qualifying commercial VLJ pilots. In a study by Burian (2007), the author analyzed accident and incident reports which offered implications for training future VLJ pilots. Significant problem areas identified in that study included poor crew/single pilot resource management, low currency, inadequate preflight planning, avionics use difficulties, and cognitive performance issues. In a separate study, the National Business Aviation Association (NBAA) Safety Committee developed a training outline that represents the minimum curriculum necessary to satisfy a very light jet transition-training program (NBAA, 2007). The NBAA Safety Committee identified the following unique potential problems for inclusion in VLJ pilot training as wake turbulence encounters, convective weather encounters, microburst/ windshear encounters, clear air turbulence/jet stream core or boundary encounters, highaltitude upset, mountain wave encounters, inadequate knowledge of high-altitude weather, physiological effect of high-altitude operations, jet blast damage, low-fuel arrivals, incorrect/less than optimum cruise altitude selection, inadequate preparation for high-rate/high speed climbs, inadequate crosswind takeoff/landing preparation, inadequate LAHSO preparation, VLJs misunderstood by ATC, single pilot adherence to checklists, FMS programming and autoflight versus manual flight control, inadequate exercise of command, recognizing single pilot red flags, lack of pilot selfevaluations, and winter operations.

After initial training and education, traditional commercial pilot career progression most often included multi-crew pilot experiences where the pilot's development progressed through stages of advancement from Second Officer to First Officer, and finally to Captain as pilot-in-command (PIC) at most airlines, charter fleets, and corporate flight departments. With single-pilot certification for VLJ operations, an innovative view of pilot training and advancement must be considered. One consideration for VLJ pilot development is incorporating the role of a mentor pilot. The NBAA Safety Committee advocates mentor pilot programs to supplement VLJ pilot transition training (NBAA, 2007). These mentor pilot programs will match very experienced pilots with VLJ transitioning pilots.

VLJ manufacturers and aviation insurance companies generally support the concept of mentor pilot relationships in order to gain acceptance by the professional flying community, and the FAA, and overcome the problem of insurability of VLJ pilots (Cobb, Thomas, \& Cobb, 2007). Research in the area of mentoring has followed several avenues. Schneier, MacCoy, and Burchman (1988) view mentoring as developing a relationship to transfer skill and knowledge, and having the 
mentor act as a model of effective behavior. This model could be applied to provide initial operating experience for pilots in single-pilot operations. Additional work by Geroy, Bray, and Venneberg (2005), adopted a characterization of mentoring as the supporting of learning and development of individuals seeking personal and professional growth, where these mentoring efforts meet both individual and organizational needs. Results of a study by DeMik (2007), stressed the critical role of mentoring as a strategic need within human resource development that fosters an environment for performance improvement.

\section{METHODOLOGY}

The researchers initially reviewed VLJ flight operations within seven companies: four of the first commercial operators of VLJ aircraft and the three leading VLJ manufacturers. The research was designed to identify each organization's experiences with pilot training and identify similarities and differences among them. It was also the intent of this study to determine if collegiate aviation could play a key role in preparing pilots for positions within this segment of the industry.

A review of the literature discussed in the previous section revealed key issues that may lead to unique potential problems for professional VLJ pilot training such as poor crew/single-pilot resource management, low currency, avionics use difficulties, single-pilot adherence to checklists, and recognizing singlepilot red flags (Burian, 2007; NBAA, 2007). Due to the infancy of commercial single-pilot VLJ operations, none of the literature, however, addresses the actual commercial operation of single-pilot VLJ aircraft. A defining feature of this study is the opportunity for the operations staff at these companies to express their personal experiences in this innovative aviation business regarding hiring, training and providing initial operating experience for their pilots.

\section{Theoretical Framework}

The theoretical framework we chose for this study was narrative inquiry. Our initial telephone survey, as established in appendix A, proved to be ineffective. Flight operations staff personnel were hesitant to provide survey information. However, they chose instead to provide in-depth conversation as opposed to staying on script to complete the survey. Since we had incomplete responses to the initial survey, no data analysis to the survey was provided in this article. Because of the in-depth discussion, the researchers continued the research as a narrative inquiry approach.

Using interviews, discussions, and an exploration of past experiences, this method allowed VLJ operations staff to convey their experience in this field in narrative form. The participants were encouraged to consider and discuss compelling and controversial issues in commercial VLJ operations through narrative expression. Their accounts provide a depth of ownership needed to explore important issues in aviation, in a way that previous VLJ studies have not considered. Hearing each staff member tell his or her experiences in VLJ pilot qualifying provides an initial understanding of what was missing in the literature regarding this new field - an understanding of the initial pilot operating experience, qualifications, and training requirements as determined by commercial VLJ business operators and manufacturers in actual operations.

A qualitative study provides a rich, comprehensive description as evidence of the experience of the participants, as opposed to calculating statistics drawn from large samples of participants (Patton, 2002). Patton also suggests that the perceptions, beliefs, and attitudes of the participants are the target of a qualitative study. The researchers do not judge the data; instead, the data is merely presented for its descriptive value and analyzed for assumptions and commonalities. A theory emerges gradually through data collection, accompanied by the researchers' continual reflection of the data. An examination of the experiences of VLJ staff regarding distinctive issues affecting pilot qualifying may be most effectively researched through a qualitative study.

A qualitative study of the experiences of VLJ staff in actual operations, in the form of a narrative inquiry, may enhance current literature on VLJ pilot qualifying through the impact of the participants' narratives. We felt that this perspective could provide a provocative method 
for our research in a field that is just now emerging. The value of this research lies in its ability to shed light on the curricular issues of commercial VLJ pilot initial operating experience, training requirements, and the role of collegiate aviation.

\section{Research Questions}

The guiding research questions for this study were:

1. What minimum pilot qualifications will VLJ air taxi operators require of pilots in order to be hired to fly their VLJ's?

2. What role can collegiate aviation programs play in preparing pilots to fly VLJs in the air taxi market?

3. What minimum time will be required with a mentor pilot prior to a new hire pilot being released to fly single-pilot in a VLJ in air taxi operations?

4. From which segment of the industry do you believe pilots will emerge for the air taxi market?

\section{Population}

The following sections describe the participants used in our study, the data collection, and data analysis process. The seven companies initially identified for this study represent the majority of the emerging VLJ field to have actual flight operational experience with commercial VLJ flight operations. Two companies, Linear Air and Pogo Jet, Inc., were later excluded from this research as they had not yet started VLJ operations. When the seven companies were first identified, these two companies were to have had VLJ operations; however, they experienced some delay in their start-up.

Since the study is a narrative inquiry and the participants' voices are central to the understandings that develop in the inquiry, we will provide a brief description of each participant before we discuss data collection. Participants were operations staff members at emerging commercial VLJ business operators and manufacturers. The following is a brief narrative on each of the five companies that had operational experience with VLJs at the time of our inquiry.
DayJet. DayJet has worked to change the way on-demand air travel works. They were the first air-taxi operator to offer accessible air travel on a per-seat basis using VLJs. Based on the premise that time is valuable, DayJet allows business travelers the freedom to set their own terms for on-demand jet service. Employing a $100 \%$ all-digital operation, DayJet is able to run a large-scale on-demand service on a per-seat basis without publishing flight schedules. In July 2002, DayJet signed a five-year agreement for the purchase of more than 1,000 Eclipse 500 jet aircraft. To date, DayJets operates approximately 65 Eclipse 500 VLJs (DayJet, 2008).

HondaJet The HondaJet fulfills one of Honda's longstanding dreams to advance mobility through personal aviation. Honda's focus is on their customers and the harnessing of advanced technologies to provide new and better mobility for people. The Honda Aircraft Company has received more than 110 orders for the \$3.65 million HondaJet, with first deliveries scheduled for 2010. On Wednesday, June 27, 2007, Honda Aircraft Company broke ground for their future world headquarters in Greensboro, N.C (HondaJet, 2008).

Imagine Air. ImagineAir is also changing the way air taxi service works by offering innovative on-demand personal air transportation service for people traveling for both business and pleasure. Their point-to-point service, between regional airports in the Southeast, is at a cost similar to those of the large commercial air carriers and lower than that of the traditional private charters. Currently equipped with five Cirrus Aircraft, ImagineAir is expanding its fleet to include three Eclipse 500 Very Light Jets, extending its service area throughout the United States and neighboring destinations (Imagine Air, 2008).

Cessna Aircraft Company. The Cessna Aircraft Company has been a leader in the general aviation piston and light/medium jet aircraft markets since 1927, having produced more than 100,000 piston-powered airplanes and another 2,000 Citation jets. The Citation Mustang, announced in 2002, was designed to fill a void in the light turbine aircraft market and 
meet the needs of tomorrow's aviation environment. The six-place Citation Mustang received full FAA type certification on September 8, 2006. Cessna currently has over 500 orders for the Citation Mustang (Cessna, 2008).

Eclipse Aviation. Eclipse Aviation was founded in 1998 with the goal of bringing the word "personal" into the aviation market. Their innovative approach to business designs, certifying, and manufacturing of the Eclipse 500 VLJ is part of the current transformation in the transportation industry. To date, Eclipse has orders for approximately 2,400 Eclipse 500 VLJ's. Full FAA type certification was achieved on September 30, 2006 (Eclipse, 2008).

\section{Data Collection}

A telephone survey (attached as appendix A) was developed to initiate dialog and determine emerging commercial VLJ operators' and manufacturers' attitudes and experiences regard-ing hiring, training and providing initial operating experience for their pilots. This method of data collection was selected because of some proven advantages it has over other methods. According to Dillman and Salant (1994), this method results in higher response rate which is especially important with a small population such as this one. Additionally, the data can be collected faster which is a key factor in a rapidly changing industry such as aviation.

Representatives of seven VLJ companies were telephoned and surveyed. Two of the seven companies were excluded from the research inquiry as they had not yet begun VLJ operations. The telephone calls were placed during normal business hours during the weekday.

Five of the seven companies provided data for this study, yielding a $71 \%$ response rate. As stated in the theoretical framework section of this article, our initial telephone survey proved to be ineffective. Flight operations staff personnel were hesitant to provide survey information. However, they provided in-depth conversation which is represented in our findings below.

\section{FINDINGS}

\section{Pilot Requirements}

A guiding question was posed inquiring about minimum pilot qualifications. Experience and sound decision-making abilities are two key points that emerged when asked this question. Meeting pilot-in-command (PIC) FAR 135 IFR minimums established by the Federal Aviation Regulations were cited by the respondents who were operating VLJ's. Additionally, flight times between 300 - 500 hours total time were given as minimums for crew members to operate as traditional first officers while gaining the requirements to meet established PIC minimums. One respondent stated these flight times may come down, over time, with the acceptance of future $a b$ initio training and mentoring programs.

\section{Hiring VLJ Pilots}

The question was posed to the respondents as to if they are or anticipate having trouble hiring pilots. With a widely held belief that the aviation industry is or will shortly be experienceing a pilot shortage, it is interesting to note that results of this inquiry did not support that belief. In fact, $100 \%$ of the respondents stated that they are not currently experiencing difficulty in hiring pilots nor do they believe their segment of the industry will experience this problem in the near future.

\section{Recruiting and Retaining Pilots}

A commonly shared belief among the respondents was that regional jet airline pilots who are looking to improve their lifestyle will be attracted to the VLJ air taxi market. Overall, respondents felt that this transition would be very smooth from the aircraft they are flying and their experience is highly desirable. Another incentive to leave their present positions is believed to be the volatility of the air carrier industry, and particularly the pay and working conditions at the regional jet airline level. With this shift occurring, one challenge that was identified was how to retain pilots who make this transition. It is a common practice for pilots to want to fly a larger aircraft and this may be a reason for them to seek employment with another company. The respondents felt that while there may currently be a shortage of pilots 
in foreign markets, the incentives linked to current domestic VLJ operations, will insulate them from what occurs in other segments of the industry.

\section{Mentoring}

When questioned about mentoring programs as an aid in providing operating experience for pilots, the companies responded with mixed enthusiasm. It is seen as a viable option for a training regime; however, the model actually being adopted is the more traditional air charter and air carrier two-man crew concept. Single-pilot VLJ commercial operations with mentoring programs were not being routinely utilized in favor of the more traditional Captain and First Officer roles for gaining flight experience and advancement. Another operational implication for the traditional twopilot crew versus single-pilot was to meet particular customer insurance requirements for multi-pilot crews. Respondents felt that this may change if it is proven that through innovative training and mentoring, a safe operation can be conducted with a sole pilot; however, this is yet to be determined.

\section{Collegiate Aviation's Role}

The respondents were questioned about glass cockpit training, placing simulators at universities, forming formal partnerships with universities and the value of collegiate aviation programs in developing courses for small singlepilot jet operations. The good news in this area of the study is that the respondents believe that collegiate aviation is properly preparing pilots for the market place. It had been hoped that this research would uncover a need for a more formal bridge program to be developed between the VLJ operators and collegiate aviation programs. This was not the case. Respondents were in general open to the idea of training being developed that would lead to pilots graduating from an aviation program and entering their segment of the market place. However, without a shortage of pilots, the companies currently are able to hire more seasoned pilots and therefore did not see an immediate need for a formal partnership with university flight programs. That being said, there was a resounding call for glass cockpit training and advanced flight deck technology training. A general focus on jet aircraft training instead of the more traditional model of pistonengine general aviation training is also seen as more beneficial in transitioning students successfully into the VLJ market place. The FAA-Industry Training Standards (FITS) program and other scenario-based flight training programs were also identified as a means to provide higher quality training. In a synopsis, it was stated that rote systems training is no longer as important as it once was, and that university programs need to focus their curriculum on 'managing' the cockpit. This shift is from one where pilots were expected to know systems, to one where their ability to analyze a situation and make a correct decision, is more valued.

\section{CONCLUSIONS}

The purpose of this study was to ascertain how commercial VLJ business operators and manufacturers view pilot selection, training, and operational experience processes unique to VLJ single-pilot commercial operations. Additionally, this study investigated the role collegiate aviation could possibly play in supplying pilots for this emerging section of the aviation industry. The findings of this study indicated that current pilot supply for commercial operations in VLJ aircraft were being met by pilots leaving regional airline operations and also from promotion within current air taxi operations. Innovative mentoring programs offered for single-pilot VLJ commercial operations were not being used in favor of more traditional Captain and First Officer roles for gaining flight experience and advancement. Another operational implication for the traditional two-pilot crew versus singlepilot was to meet particular customer insurance requirements for multi-pilot crews. With regard to the role of collegiate aviation within the emerging VLJ industry, respondents valued collegiate aviation's past preparation of industry pilots and offered suggestions in adjusting curriculum away from traditional systems training to one of flight deck management. Results also indicated that while there was no immediate need for formal relationships between VLJ industry and collegiate aviation, 
respondents were open to the idea of future collaboration.

Research on pilot qualification and collegiate aviation's role regarding VLJ flight operations could continue in several directions. First, other aspects of VLJ pilot training and qualifying may be affected through the growth of VLJ operations. Second, longer-term studies that compare the effectiveness of mentoring programs versus traditional advancement from First Officer to Captain may change attitudes and regulations for single-pilot operations for VLJ aircraft and therefore provide safe and efficient use of VLJ aircraft in commercial operations. Third, and perhaps most fascinating as the VLJ markets grow, studies could explore how collegiate aviation might have a more active role in VLJ pilot education. This role may be enhanced through housing VLJ simulators on campus in partnership with VLJ operators and manufacturers, developing formal bridge programs, researching the advantages or disadvantages of mentoring versus advancement through multi-crew operations, and overall formal partnerships with the VLJ industry.

In conclusion, the results of this study provide some initial insights into emerging VLJ flight operations. This research and other research to follow will contribute to knowledge of the disadvantages - and possible advantages of the establishment of mentoring programs for single-pilot VLJ flight operations. The mixed results of this study suggest that we have much more to learn about VLJ pilot selection, training, operational experience processes, and the role of collegiate aviation for this emerging segment of the industry. 


\section{REFERENCES}

Bonnefoy, P. A., \& Hansman, R. J. (2007). Potential impacts of very light jets on the national airspace system. Journal of Aircraft, 44(4), 1318-1326.

Brown, A. S. (2007). Very light and fast. Mechanical Engineering, 129(1), 24-29.

Burian, B. K. (2007). Very light jets in the national airspace system. Proceedings of the 14th International Symposium on Aviation Psychology.

Cessna Aircraft Company (2008). Retrieved April 4, 2008 from http://cessna.com/

Cobb, R., Thomas, J. L., \& Cobb, L. A. (2007). The very light jet arrives: Stakeholders and their perceptions. Journal of Air Transportation, 12(1), 87-97.

DayJet. (2008). Retrieved April 2, 2008, from http://www.dayjet.com/

DeMik, R. J. (2007 February 28). Coaching, counseling, and mentoring: A strategic need in training and development. Paper presented at the meeting of the Annual Conference of the Academy of Human Resource Development. Indianapolis, IN.

Eclipse Aviation Corp. (2008). Retrieved April 3, 2008 from http://www.eclipseaviation.com/

Geroy, G. D., Bray, A., \& Venneberg, D. L. (2005). The CCM model: A management approach to performance optimization. Performance Improvement Quarterly, 18(2), 19-37.

Government Accountability Office (2007). Very light jets: Several factors could influence their effect on the national airspace system (GAO Publication No. 07-1001). Washington, DC: U.S. Government Printing Office.

HondaJet (2008). Retrieved April 4, 2008 from http://hondajet.honda.com/default.aspx?bhcp=1

Imagine Air (2008). Retrieved April 2, 2008 from http://www.flyimagineair.com/

NBAA. (2007). NBAA Training Guidelines for Single Pilot Operations of Very Light Jets and Technically Advanced Aircraft. Retrieved December 11, 2007, from http://web.nbaa.org

Patton, M.Q. (2002). Qualitative research and evaluation methods (3rd ed.). Thousand Oaks, CA: Sage Publications.

Prather, C. D., \& Hawkins, J. C. (2007). The impacts of VLJs on Tennessee airports: A case study. Collegiate Aviation Review, 25(2), 38-50.

Salant, P. \&. D., D.A. (1994). How to conduct you own survey. NY: John Wiley and Sons, Inc.

Schneir, C. E., MacCoy, D., \& Burchman, S. (1988). Unlocking employee potential: Developing skills. Management Solutions, 26(1), 26-30.

Strait, B. (2007). Very light jet update for commercial pilots. Very Light Jet Magazine. Retrieved December 11, 2007, from http://www.verylightjetmagazine.com/articles/2007_05.pdf

Trani, A. A., Baik, H., Hinze, N., Ashiabor, S., Viken, J. K., \& Cooke, S. (2005). Integrating air transportation system demand predictions in preliminary aircraft design. Proceedings of the 5th Aviation, Technology, Integration, and Operations Conference.

Trani, A. A., Baik, H., Swingle, H., \& Senanu, A. (2003). Integrated model for studying small aircraft transportation. Transportation Research Record, 1850, 1-10. 


\section{APPENDIX A}

Very Light Jets: Pilot Qualifications and Collegiate Aviation's Role

\section{1.) Pilot Qualifications Hiring Criteria}

Mark the degree to which you would emphasize the importance of each category of flight experience for VLJ pilot interviewees.

\begin{tabular}{|l|l|l|l|}
\hline \multicolumn{1}{|c|}{$\begin{array}{c}\text { Pilots interviewing with } \\
\text { time in }\end{array}$} & Low Emphasis & Moderate Emphasis & High Emphasis \\
\hline $\begin{array}{l}\text { Single-Engine Recip } \\
\text { Aircraft }\end{array}$ & & & \\
\hline $\begin{array}{l}\text { Single-engine turbo-prop } \\
\text { or pressurized single } \\
\text { engine aircraft }\end{array}$ & & & \\
\hline $\begin{array}{l}\text { Turbo-prop or left seat } \\
\text { Cabin Class Twin }\end{array}$ & & & \\
\hline Left seat of a previous jet & & & \\
\hline
\end{tabular}

\section{2.) Mentoring}

With regard to the following four categories of new hire pilots, what would you consider to be the targeted minimum and maximum operating time with a mentor pilot prior to release to fly single-pilot VLJ operations?

\begin{tabular}{|l|l|l|l|}
\hline $\begin{array}{c}\text { Pilot Transitioning } \\
\text { From }\end{array}$ & No Mentor Time & $\begin{array}{c}\text { Desired Minimum } \\
\text { Mentor Time }\end{array}$ & $\begin{array}{c}\text { Desired Maximum } \\
\text { Mentor Time }\end{array}$ \\
\hline $\begin{array}{l}\text { Single- Engine Recip } \\
\text { Aircraft }\end{array}$ & & & \\
\hline $\begin{array}{l}\text { Single-engine turbo- } \\
\text { prop or pressurized } \\
\text { single engine aircraft }\end{array}$ & & & \\
\hline $\begin{array}{l}\text { Turbo-prop or left } \\
\text { seat Cabin Class } \\
\text { Twin }\end{array}$ & & & \\
\hline $\begin{array}{l}\text { Left seat of a } \\
\text { previous jet }\end{array}$ & & & \\
\hline
\end{tabular}

3.) What group of the industry do you believe your pilots will come from?

\begin{tabular}{|l|l|l|l|}
\hline \multicolumn{1}{|c|}{ Industry Experience } & Absolutely Not & Possibly, based upon? & Most Likely \\
\hline Part 91 & & & \\
\hline Part 135 Operators & & & \\
\hline Part 121 Operations & & & \\
\hline Military & & \\
\hline $\begin{array}{l}\text { Straight out of Collegiate } \\
\text { Aviation Program }\end{array}$ & & & \\
\hline
\end{tabular}




\section{4.) Collegiate Aviations Role}

Mark the degree to which you believe collegiate aviation could play a role in training pilots to meet your future needs

\begin{tabular}{|l|l|l|l|}
\hline \multicolumn{1}{|c|}{ Collegiate Aviation Role } & No & Would be considered & Yes \\
\hline $\begin{array}{l}\text { Developing courses for small single-pilot } \\
\text { jet operations }\end{array}$ & & & \\
\hline Glass Cockpit Training & & & \\
\hline $\begin{array}{l}\text { Establish partnerships with Collegiate } \\
\text { Aviation Programs }\end{array}$ & & & \\
\hline $\begin{array}{l}\text { Sharing the cost of training i.e. } \\
\text { Purchasing simulators to be located at a } \\
\text { University etc. }\end{array}$ & & & \\
\hline
\end{tabular}

Other ways that collegiate aviation could help meet your need for qualified pilots... 